\title{
Optimization of Reactor Temperature and Catalyst Weight for Plastic Cracking to Fuels Using Response Surface Methodology
}

\author{
I. Istadi *, S. Suherman, and Luqman Buchori \\ Department of Chemical Engineering, Diponegoro University, Jl. Prof. Sudharto, \\ Kampus UNDIP Tembalang, Semarang 50239, Indonesia
}

Received: 10th July 2010; Revised: 18th September 2010; Accepted: 19 September 2010

\begin{abstract}
The present study deals with effect of reactor temperature and catalyst weight on performance of plastic waste cracking to fuels over modified catalyst waste as well as their optimization. From optimization study, the most operating parameters affected the performance of the catalytic cracking process is reactor temperature followed by catalyst weight. Increasing the reactor temperature improves significantly the cracking performance due to the increasing catalyst activity. The optimal operating conditions of reactor temperature about $550{ }^{\circ} \mathrm{C}$ and catalyst weight about 1.25 gram were produced with respect to maximum liquid fuel product yield of $29.67 \%$. The liquid fuel product consists of gasoline range hydrocarbons $\left(\mathrm{C}_{4}-\mathrm{C}_{13}\right)$ with favorable heating value $(44,768 \mathrm{~kJ} / \mathrm{kg})$. (C) 2010 BCREC UNDIP. All rights reserved
\end{abstract}

Keywords: plastic waste; Residual Catalytic Cracking; optimization; central composite design; response surface methodology

\section{Introduction}

One of the alternative ways to overcome the abundance plastics waste problem and also to increase its economic value is by converting plastics waste into fuels using pyrolysis process. By this process, plastic can be converted into monomers, fuels, and chemicals. Despite of that, fuels from chemical recycling process also can be used as alternative energy, replacing natural gas and crude oils. High reactor temperature on thermal pyrolysis plastics, such as polyolefines, polyethylene and polypropylene are undesirable. The environmentally benign methods is its conversion to fuels by utilizing the catalyst waste after modified. Catalytic cracking of plastic waste over acidic solid catalysts (zeolites-based catalysts) has been widely proposed by previous researchers as an interesting solution subject to reduce the cracking temperature [1-4].

Thermal cracking is the simplest method where waste thermoplastic polymers heated in high temperature. The heating process affects macro structure of plastic moleculs to be degradated into smaller moleculs and forming short enchain hydrocarbons. Therefore, catalytic cracking becomes one of interesting alternative solution to solve this problem. Accordingly, a great variety of heterogeneous catalysts have been found for the

\footnotetext{
* Corresponding Author.

E-mail address: i.istadi@undip.ac.id (I. Istadi),

Tel: +62-24-7460058, Fax: +62-24-76480675
} 
catalytic cracking of plastics, such as: (a) silica alumina [5-7], (b) conventional commercial zeolites (HZSM-5, HBeta, HY, etc.) [4-5,7-12], (c) fresh and spent FCC catalysts, [13-17], (d) mesostructured catalysts (MCM-41, FSM-16, Al-SBA-15, AlUTD-1) [18-20], and (e) solid superacid catalyst $\left(\mathrm{ZrO}_{2} / \mathrm{SO}_{4}{ }^{2}\right)$ [18]. The previous researchers [4-20] focused on several solid acid catalysts as well as solid superacid for catalytic cracking of plastic waste by pyrolysis of polyethylene and/or polypropylene to yield gasoline. The solid acid catalysts possessing strong acid sites such as zeolite ZSM-5 and silicaalumina accelerated the degradation of plastic polymer into gases which resulted in low liquid yields. In contrast, Sakata et al. [7] suggested that the degradation mechanism of polyolefins over mesoporous folded silica is strongly affected by the specific feature of the hexagonal large pore structure of the catalyst but not by the acid sites. Uemichi et al. $[8,10]$ found that large pores and moderate acidity of the silica-alumina loaded in the upper layer operated favorably to catalyze the degradation of polyethylene into liquid hydrocarbons. Cardona \& Corma [14] suggested a semicontinuous reactor that allows carrying out efficiently the catalytic cracking of PP. They found that the the formation of mesopores in the zeolite strongly improves the cracking activity. A clear trend of liquid hydrocarbon formation was observed by Akpanudoh et al. [15] with the acidity content during the catalytic degradation of polyethylene over the commercial cracking catalysts. Serano et al. [20] found that of the solid superacids studied, the $\mathrm{ZrO}_{2} / \mathrm{SO}_{4}{ }^{2-}$ catalyst possesses the highest cracking activity and the approximate order of cracking activity is $\mathrm{ZrO}_{2} / \mathrm{SO}_{4}{ }^{2-}>\mathrm{Al}_{2} \mathrm{O}_{3} / \mathrm{SO}_{4}{ }^{2-}>\mathrm{Pt} / \mathrm{Al}_{2} \mathrm{O}_{3} / \mathrm{SO}_{4}{ }^{2-}>$ no catalyst. The stronger the cracking catalyst, the lighter the aliphatic products and the more abundant the isomeric constituents. Serrano et al. [18-20] suggested that the high surface area and large pores present in HMCM-41 are responsible for the high conversions obtained with this catalyst. Significant differences are observed in the product distribution: n-HZSM-5 shows the highest selectivity toward $\mathrm{C}_{1}-\mathrm{C}_{4}$ gaseous hydrocarbons (50 wt \%), HBeta leads mainly to liquid hydrocarbons in the range $\mathrm{C}_{5}-\mathrm{C}_{12}(60 \mathrm{wt} \%)$, whereas HMCM-41 yields both $\mathrm{C}_{5}-\mathrm{C}_{12}(54 \mathrm{wt} \%)$ and $\mathrm{C}_{13}-\mathrm{C}_{30}(32 \mathrm{wt} \%)$ fractions. The great majority of the previous works focused on the catalyst finding particularly on fresh catalyst, leading to the appropriate catalyst for plastic or polymer conversion to fuels and chemicals.

In terms of modeling and optimization in catalytic cracking process, there is only a few researcher focused on improving the process optimization. Most of previous researchers concerned on catalyst finding. Optimization of operating conditions including its sensitivity analysis corresponding to specific catalyst and reactor is important to reach the maximum yield or conversion of fuels (liquid and/or gas). In this paper, the simultaneous modeling and optimization is developed for the catalytic cracking process including effect of each process parameters and utilization of modified catalyst. The modeling and optimization used a Response Surface Methodology (RSM) tool. A Central Composite Design (CCD) method was utilized to design the experimental works to fit the model proposed.

\section{Materials and Methods}

\subsection{Catalyst Preparation and Materials of Research}

Catalyst used in this research was obtained from a Residual Catalytic Cracking (RCC) petrochemical company in Indonesia. The catalyst modification (physical and chemicals treatments) in this research is purposed to recycle or to utilize the waste. The catalyst pretreatment was done by soaking the catalyst within $\mathrm{H}_{2} \mathrm{SO}_{4} 0.1 \mathrm{~N}$ solution for 60 minutes with stirring. The solution was then filtered and wash using distilled water. After the treatments, the catalyst was dried overnight at 110 $\mathrm{oC}$ in an oven (MEMMERT) and therefore was calcined at $550{ }^{\circ} \mathrm{C}$ for 3 hours in a programmable box furnace (NEY VULCAN 3-550). The resulted powder was crushed into the desired size. The plastic wastes sample were cut into smaller chips. Fifteen grams of mixed plastic waste was used in each experimental run. Total catalyst weight used for each experimental run was based on the experimental design. Here, 60 minutes cracking time was needed to make sure that the cracking was finished (in fact the cracking process only needs about 30 minutes in average) .

\subsection{Catalyst Testing}

Catalytic performances of plastic cracking to fuels were tested in a fixed bed reactor equipped with an electric heater (local brand - self fabricated). The installation set of equipment for catalytic testing of cracking process is depicted in Figure 1. The reactor was built from stainless steel tube with a diameter of 1 inch which put inside the electric heater. Reactor temperature was measured and controlled by a digital temperature controller (Autonics). The modified RCC catalyst was put in the center of the reactor (below the plastic sample) 


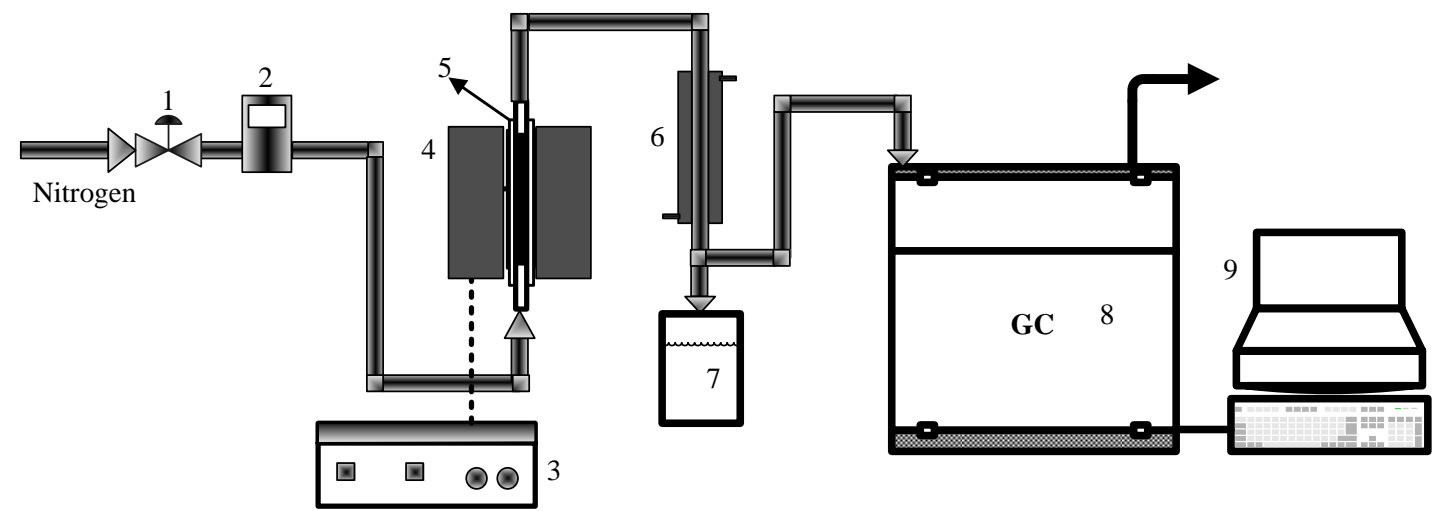

Figure 1. Experimental setup of catalytic cracking of plastic waste. (1). Gate Valve, (2). Flowmeter, (3). Temperature Controller, (4). Split Tube Furnace, (5). Fixed Bed Reactor, (6). Condensor, (7). Liquid fuel trap, (8). GC-MS, (9). Personal Computer

where the melted plastic sample was mixed with the catalyst. A glass wool was plugged below the catalyst to avoid overflow of the liquid plastic. The glass wool was also put above the catalyst in order to support a second catalyst at above the plastic sample. The second catalyst at the top of reactor was purposed to crack the longer hydrocarbon chain of plastic vapor.

Before reaction, the reactor was flushed by nitrogen flow (100 $\left.\mathrm{cm}^{3} / \mathrm{min}\right)$ for 15 minutes. The reactor was heated up to certain temperature based on the reactor temperature variable in experimental design. During the process, vapor product (cracked substance) was flowed through a condenser (HUBER; $\mathrm{T}=-20-200{ }^{\circ} \mathrm{C}$ ) in order to condense the vapor to form liquid fuel, while the non condensable gas was collected in a gas sampling pot. The liquid fuel product was stored in a flask and analyzed using a gas chromatography mass spectrometry (GC-MS) (SHIMADZU QP2010S) equipped with RTX-5 column.

Table 1. Range and level of independent variable using Central Composite Design (CCD)

\begin{tabular}{lccccc}
\hline \multirow{5}{*}{ Factors $(X)$} & \multicolumn{5}{c}{ Range and Levels } \\
\cline { 2 - 6 } & $(-a)$ & $(-1)$ & $(0)$ & $(+1)$ & $(+a)$ \\
\hline $\begin{array}{l}\text { Reactor Tem- } \\
\text { perature }\left(X_{1}\right)\end{array}$ & 479 & 500 & 550 & 600 & 621 \\
$\begin{array}{l}\left.{ }^{\circ} \mathrm{C}\right] \\
\text { Catalyst Weight } \\
\left(X_{2}\right) \text { [grams] }\end{array}$ & 0.9 & 1.0 & 1.25 & 1.5 & 1.6 \\
\hline
\end{tabular}

\subsection{Response Surface Methodology}

The responses and the corresponding factors are modeled and optimized using the response surface methodology (RSM) [21-23]. The RSM technique is aimed for: (a) designing of experiments to provide adequate and reliable measurements of the response, (b) developing a mathematical model having the best fit to the data obtained from the experimental design, and (c) determining the optimal value of the independent variables that produces maximum or minimum value of the response. In this paper, the design of experiment and the response surface analysis were employed by utilizing STATISTICA version 6 software (StatSoft Inc., Tulsa, USA).

Two independent variables or factors, namely, reactor temperature $\left({ }^{\circ} \mathrm{C}\right)$ and catalyst weight (grams). The ranges of independent variables were chosen based on the conditions from the exploratory test for finding the ranges of variables prior to optimization. The ranges and levels used in the experimental work are given in Table 1 in which $X_{1}$ denotes reactor temperature $\left({ }^{\circ} \mathrm{C}\right)$, and $X_{2}$ denotes catalyst weight (grams).

\subsection{Mathematical Model Development and Fitting}

A quadratic polynomial equation was developed to predict the response as a function of independent variables and their interactions [2123]. In general, response for the quadratic polynomials is described in Eq. (1):

$$
Y=\beta_{0}+\sum_{j=1}^{2} \beta_{j} X_{j}+\sum_{j=1}^{2} \beta_{j j} X_{j}^{2}+\sum_{i<j} \beta_{i j} X_{i} X_{j}
$$


In this equation, $\mathrm{Y}$ is the predicted response, $\beta_{o}$ is the intercept coefficient, $\beta_{j}$ are the linear terms, $\beta_{i j}$ are the squared terms, $\beta_{i j}$ are the interaction terms, and $X_{i}$ and $X_{j}$ represent the independent variables. For each experimental factor the variance was partitioned into components, linear, quadratic and interaction, in order to assess the adequacy of the second order polynomial function and the relative importance or significance of the terms.

Three-dimensional response surfaces and contour plots were used for facilitating a straightforward examination of the influence of experimental variables on the responses. The individual response surface and the contour plots were created by holding both variables constant at their center points. Coefficients of the models for three responses were estimated with multiple regression analysis. The fit quality of the models was judged from their coefficients of correlation and determination. The adequacy of each model was also checked with the analysis of variance (ANOVA) using Fisher $F$-test [21-24]. Significance of each equation parameter for each response was assessed by $p$-value and Student's $t$-test. The significance test is purposed to determine the relationship between the response variable and a subset of the independent variables.

\section{Results and Discussion}

\subsection{Development and Testing of Response Surface Methodology (RSM)}

This section shows that the Response Surface Methodology simulation focused on effect of reactor temperature and catalyst weight on yields of liquid and gas fuel in a catalytic fixed bed reactor. The mathematical model and simulations were developed based on design of experiment (DOE) developed by using the central composite design (CCD) as presented in Table 1. The experimental data used for fitting the RSM model are presented in Table 2. In the table the experimental data in terms of yields of liquid and gas fuels with respect to operating conditions variation (reactor temperature as $X_{1}$ and catalyst weight as $X_{2}$ ) are presented. Fitness of mathematical model in terms of comparison between observed and predicted value is examined and depicted in Figures 2 and 3 for liquid and gas fuels yield, respectively. From the figures, the model seems to be fit well to the experimental data which proven by sufficient determination coefficients $\left(\mathrm{R}^{2}\right)$ of 0.81 and 0.83 for liquid and gas fuels yield models, respectively. The sufficient $R^{2}$ implies a good fitting between the observed (experimental) and the predicted values .

\subsection{Optimization of Liquid Fuel Yield}

A maximum liquid fuel yield response was

Table 2. Results of experiments based on the central composite design

\begin{tabular}{ccccccc}
\hline \multirow{2}{*}{ Run } & \multicolumn{2}{c}{ Experimental Design Matrix } & & \multicolumn{2}{c}{ Experimental Results *) } \\
\cline { 2 - 3 } \cline { 5 - 6 } & $\begin{array}{c}\text { Reactor } \\
{ }^{\circ} \mathrm{C}\left(X_{1)}\right.\end{array}$ & Temperature, & $\begin{array}{c}\text { Catalyst Weight, } \\
\text { gram }\left(X_{2}\right)\end{array}$ & & $\begin{array}{c}\text { Liquid } \\
\text { Yields, } \%\left(Y_{1}\right)\end{array}$ & $\begin{array}{c}\text { Product } \\
\% Y_{2}\end{array}$ \\
\hline 1. & 500 & 1.00 & & 15.09 & 26.94 \\
2. & 500 & 1.50 & & 20.57 & 27.34 \\
3. & 600 & 1.00 & & 19.42 & 29.09 \\
4. & 600 & 1.50 & & 24.18 & 22.45 \\
5. & 479 & 1.25 & & 18.23 & 18.38 \\
6. & 621 & 1.25 & & 23.57 & 25.26 \\
7. & 550 & 0.90 & & 27.75 & 31.98 \\
8. & 550 & 1.60 & & 28.83 & 31.04 \\
9. & 550 & 1.25 & & 29.04 & 28.44 \\
10. & 550 & 1.25 & & 29.25 & 29.07 \\
11. & 550 & 1.25 & & 29.67 & 30.33 \\
12. & 550 & 1.25 & & 30.18 & 27.63 \\
13. & 550 & 1.25 & & & \\
\hline
\end{tabular}

Note: Pressure : atmospheric; Plastic sample weight : 15 gram; total cracking time: 100 minutes

*) The yields data (with catalyst) was calculated from experimental yields results minus the yields without catalyst 


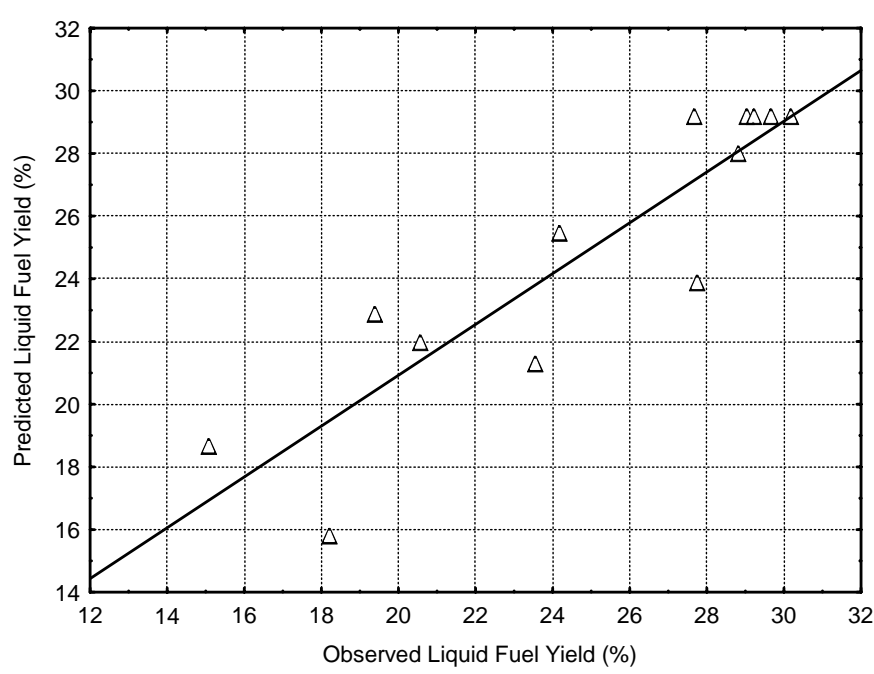

Figure 2. Observed versus predicted values formodel fitting of liquid fuel yield $\left(\mathrm{R}^{2}=0.81\right)$

obtained using RSM located at the simultaneous optimal factors. Coefficients of the liquid fuel yield model proposed in Eq. (1) were estimated using multiple regression analysis in the RSM. Finally, the response surface model of the liquid fuel yield $\left(Y_{1}\right)$ is presented in Eq. (2):

$$
\begin{aligned}
Y_{1} & =29.1772+3.8681 X_{1}-10.4957 X_{1}{ }^{2} \\
& +2.7898 X_{2}-3.579 X_{2}{ }^{2}-0.3607 X_{1} X_{2}
\end{aligned}
$$

The regression coefficients of Eq. (2) with $\mathrm{R}^{2}=0.81$

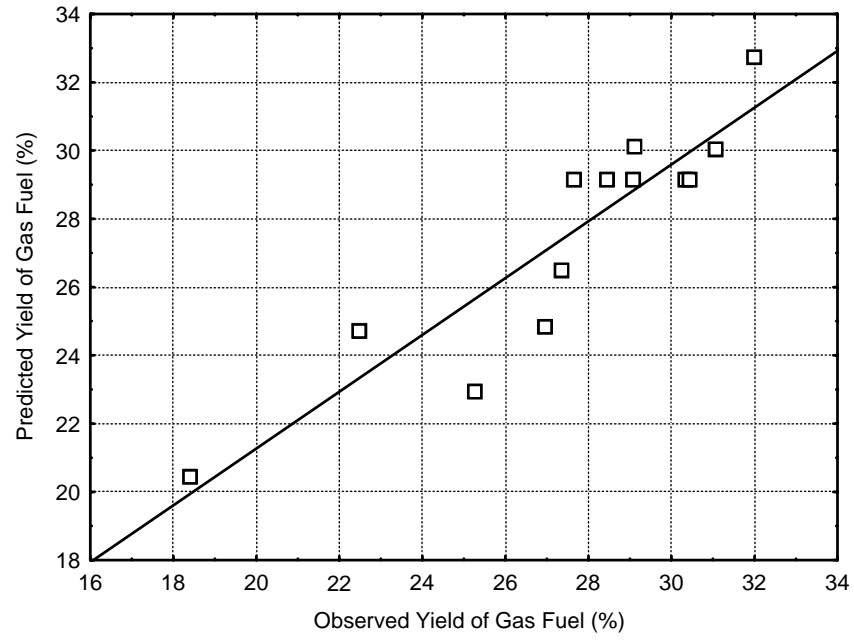

Figure 3. Observed versus predicted values for model fitting of gas fuel yield $\left(\mathrm{R}^{2}=0.83\right)$

Table 3. ANOVA Results for Liquid Fuel Yield Model

\begin{tabular}{lcccc}
\hline Source & $\begin{array}{c}\text { Sum of } \\
\text { square }\end{array}$ & $\begin{array}{c}\text { Degree } \\
\text { of free- } \\
\text { dom }\end{array}$ & $\begin{array}{c}\text { Mean } \\
\text { Square }\end{array}$ & $\begin{array}{c}\text { F- } \\
\text { value }\end{array}$ \\
\hline SS re- & 261.39 & 5 & 261.39 & 31.59 \\
gression & & 7 & 8.28 & \\
SS error & 57.93 & 7 & & \\
SS total & 306.10 & 12 & & \\
\hline
\end{tabular}

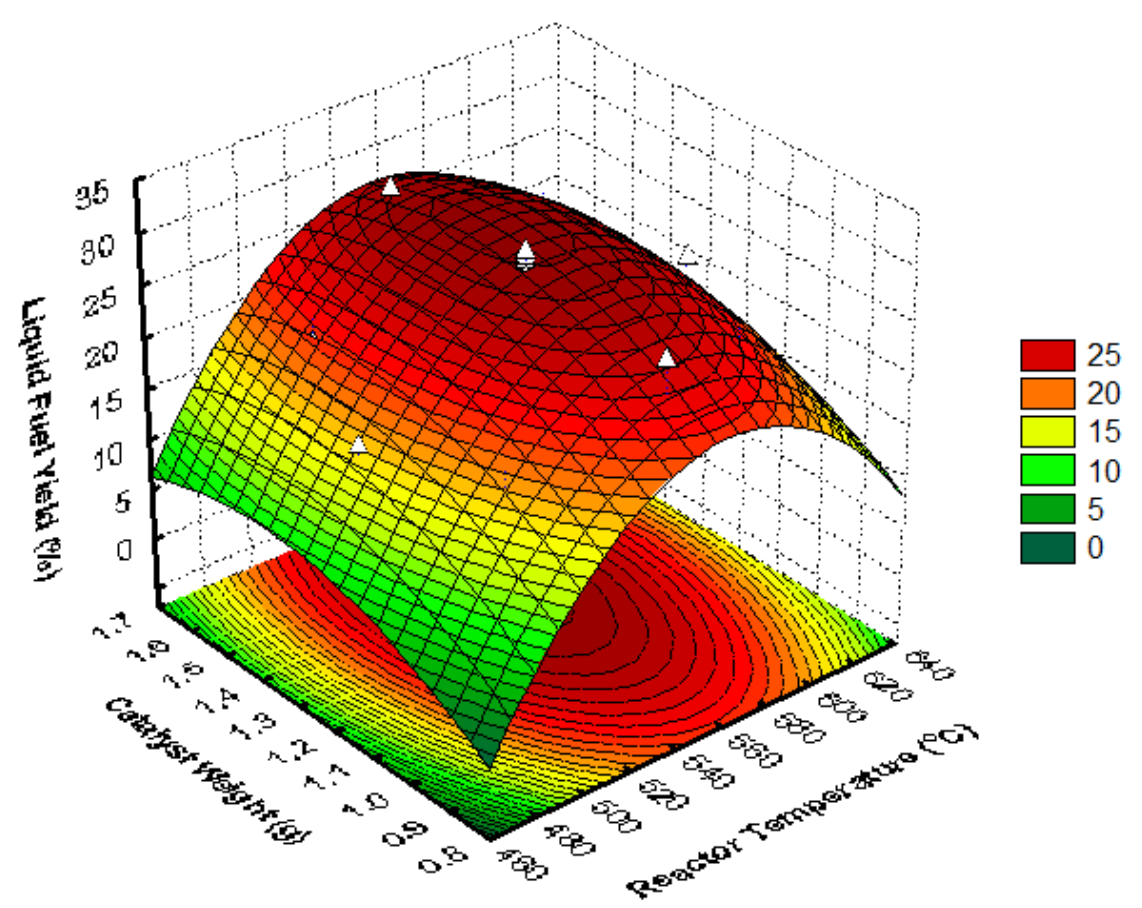

Figure 4. Surface plot of liquid fuel yield model as function of reactor temperature and catalyst weight 


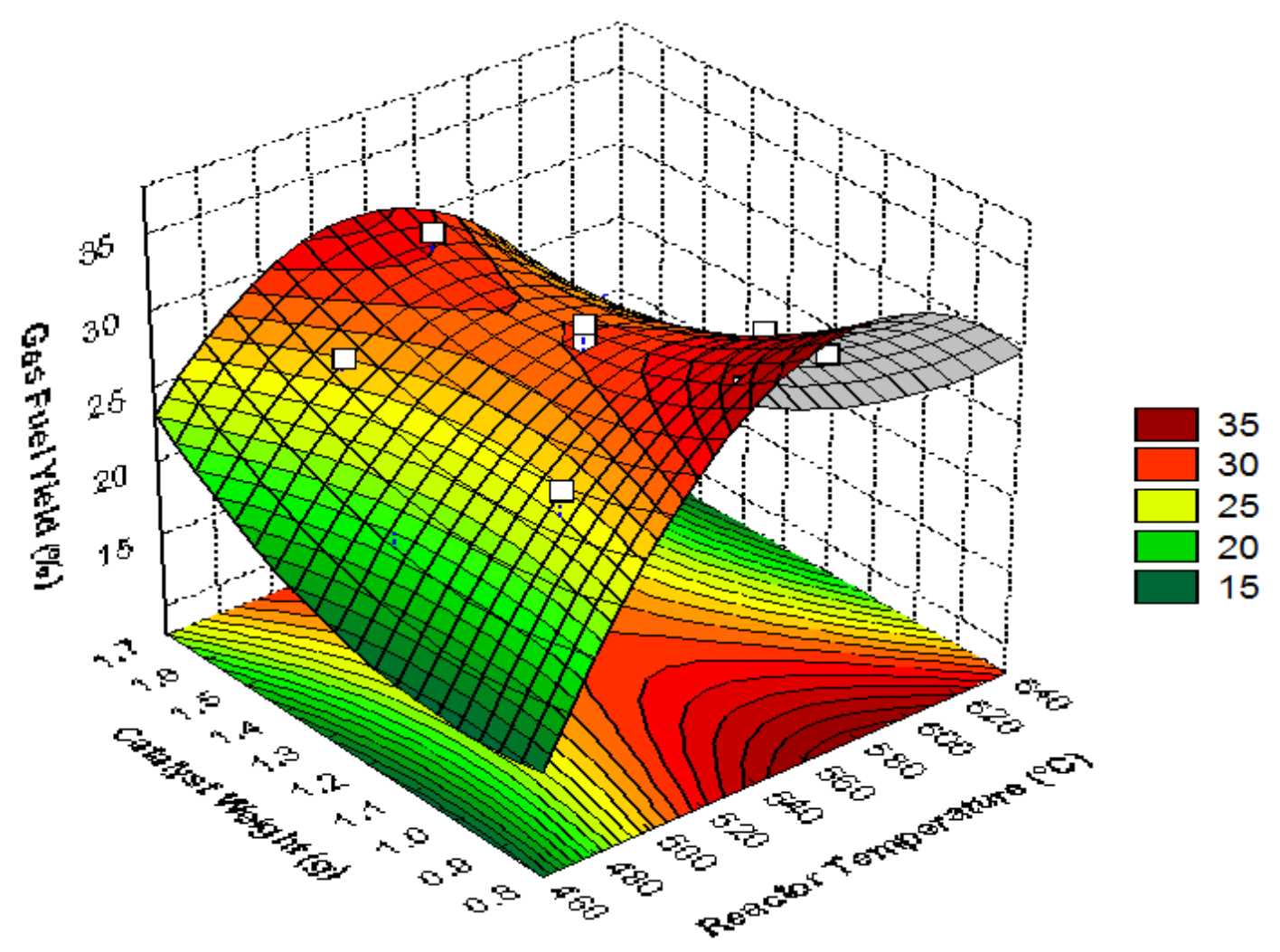

Figure 5. Surface plot of gas fuel yield model as function of reactor temperature and catalyst

implies a reasonable fit between the experimental and the predicted values. The determination coefficient infers that $81 \%$ of the total variation in the response is justified by the fitted model. The coefficient of correlation $(\mathrm{R}=0.90)$ of the liquid fuel yields model indicates a good correlation between the experimental and predicted values. The fit quality of the liquid fuel yields model was attested with analysis of variance (ANOVA) [21-24] as revealed in Table 3. From Table 3, the calculated F-value of liquid fuel yields at 31.59 is remarkably higher than that of $\mathrm{F}$ distribution table $\left(F_{0.05 ; 5,7}=\right.$ $3.971)$ at $5 \%$ level of significance implying the null hypothesis $\left(H_{0}\right)$ is rejected and the alternative hypothesis $\left(H_{1}\right)$ is accepted at $5 \%$ level of

Table 4. ANOVA Results for Gas Fuel Yield Model

\begin{tabular}{ccccc}
\hline Source & $\begin{array}{c}\text { Sum of } \\
\text { square }\end{array}$ & $\begin{array}{c}\text { Degree } \\
\text { of free- } \\
\text { dom }\end{array}$ & $\begin{array}{c}\text { Mean } \\
\text { Square }\end{array}$ & $\begin{array}{c}\text { F- } \\
\text { value }\end{array}$ \\
\hline SS regresi & 131.57 & 5 & 131.57 & 32.53 \\
SS error & 28.32 & 7 & 4.05 & \\
SS total & 169.08 & 12 & & \\
\hline \multicolumn{1}{c}{$\mathrm{R}^{2}$} & 0.8325 & & & \\
\hline
\end{tabular}

significance. It is suggested that the variation accounted for by the model is significantly greater than the unexplained variation.

Three dimensional surface plot of the liquid fuel yield model as function of reactor temperature and catalyst weight is depicted in Figure 4. From the figure, high reactor temperature leads to a high liquid fuel yield, but consequently the liquid fuel yield decreases at temperature higher than $550^{\circ} \mathrm{C}$. From the figure, it is suggested that the reactor temperature parameter has more significant effect on the targeted product than the catalyst weight. However, the catalyst weight only gives slight effect on the yields. The phenomenon is acceptable because the reactor temperature relates with the energy supply required for the catalytic cracking process, while the catalyst weight is related to contact efficiency between the vaporized/liquefied plastic sample and the catalyst particles. The thermal energy is required for activation of the catalyst itself to do the catalytic cracking process. The catalyst gives alternative routes of reaction mechanism so that the activation energy is lower. The energy for activation the active sites should be sufficient as the catalyst used is not fresh catalyst.

The position of the optimal conditions for liquid fuel yields is depicted in Figure 4 with respectt to 
optimal operating conditions of reactor temperature $550{ }^{\circ} \mathrm{C}$ and of catalyst weight 1.25 grams. The optimum operating conditions give maximum yields of liquid fuel product of $29.67 \%$.

Effect of reactor temperature and catalyst weight is simulated in Figures 4 on liquid fuel yield. From the figures, yield of liquid fuel is affected by reactor temperature significantly. It is suggested that the reactor temperature parameter gives most significant effect on the targeted production of liquid and gas fuels. The significant effect of reactor temperature towards yield or concentration of volatile component (liquid/gas fuel) shows in agreement with results of Babu \& Chaurasia [2], Uemichi et al. [8,10], Lin \& Yang [9], and Yoona et al. [28]. However, the ranges of experimental reactor temperature were different. It is concluded that under appropriate reaction conditions and suitable catalysts can have the ability to control both the product yield and product distribution from polymer degradation, potentially leading to a cheaper process with more valuable products .

\subsection{Optimization of Gas Fuel Yield}

A maximum gas fuel yield response was also obtained by the RSM method which is located at the simultaneous optimal factors. Response surface mathematical model of gas fuel yields $\left(Y_{2}\right)$ is presented in Equation (3):

$$
\begin{aligned}
Y_{2}= & 29.1784+1.7481 X_{1}-7.4297 X_{1}^{2} \\
& -1.90799 X_{2}+2.2437 X_{2}{ }^{2}-3.5235 X_{1} X_{2}
\end{aligned}
$$

Regression coefficients of the Equation (3) with $\mathrm{R}^{2}=0.83$ infers that $83 \%$ of the total variation in the response is justified by the fitted model. The fit quality of the gas fuel yield model was also examined using analysis of variance (ANOVA) [2124 ] as revealed in Table 4 . The calculated $F$-value of gas fuel yield of 32.53 is remarkably higher than that of $\mathrm{F}$ distribution table $\left(F_{0.05 ; 5,7}=3,971\right)$ at $5 \%$ level of significance. The $F$-test result implies that the null hypothesis $\left(H_{0}\right)$ is rejected and the alternative hypothesis $\left(H_{1}\right)$ is accepted at $5 \%$ level of significance.

Surface plot of the gas fuel yield model is depicted in Figure 5. From the figure, high reactor temperature also leads to a high gas fuel yield and affected by catalyst weight slightly. The reactor temperature relates with the energy supply required for the catalytic cracking process, while the catalyst weight is related to contact efficiency
Table 5: Identification and composition of main hydrocarbons components of liquid fuels product

\begin{tabular}{|c|c|c|}
\hline $\begin{array}{l}\text { Retention } \\
\text { time } \\
\text { (minutes) }\end{array}$ & $\begin{array}{l}\text { Main Identified Com- } \\
\text { pound }\end{array}$ & $\begin{array}{l}\text { Composi- } \\
\text { tion (\%) }\end{array}$ \\
\hline 2.225 & $\begin{array}{l}\mathrm{C}_{4} \mathrm{H}_{8} \text { (2-Methyl-1- } \\
\text { propene) }\end{array}$ & 3.33 \\
\hline 2.408 & $\begin{array}{l}\mathrm{C}_{5} \mathrm{H}_{10} \text { (2-Methyl-2- } \\
\text { butene) }\end{array}$ & 3.44 \\
\hline 2.650 & $\begin{array}{l}\mathrm{C}_{6} \mathrm{H}_{12}(3-\text { Methyl-2- } \\
\text { pentene) }\end{array}$ & 8.08 \\
\hline 3.208 & $\begin{array}{l}\mathrm{C}_{7} \mathrm{H}_{14}(3-\text { Methyl-2- } \\
\text { hexene) }\end{array}$ & 13.66 \\
\hline 3.983 & $\mathrm{C}_{7} \mathrm{H}_{8}$ (Methyl benzene) & 10.96 \\
\hline 5.133 & $\begin{array}{l}\mathrm{C}_{9} \mathrm{H}_{18} \text { (Propil- } \\
\text { Cyclohexane) }\end{array}$ & 10.26 \\
\hline 5.308 & $\begin{array}{l}\mathrm{C}_{9} \mathrm{H}_{18} \text { (2,4-dimethyl-1- } \\
\text { Heptane) }\end{array}$ & 12.00 \\
\hline 15.175 & $\mathrm{C}_{13} \mathrm{H}_{28}$ (n-tridecanol) & 38.27 \\
\hline
\end{tabular}
using GC-MS analysis

between the vaporized/liquefied plastic sample and the catalyst particles. The phenomenon is acceptable because the reactor temperature relates with the energy supply required for the catalytic cracking process, while the catalyst weight is related to contact efficiency between the vaporized/liquefied plastic sample and the catalyst particles. The thermal energy is required for activation of the catalyst itself to do the catalytic cracking process. The catalyst gives alternative routes of reaction mechanism so that the activation energy is lower. The energy for activation the active sites should be sufficient as the catalyst used is not fresh catalyst.

From the optimization, optimal operating conditions are reactor temperature of $550{ }^{\circ} \mathrm{C}$ and catalyst weight of 0.9 gram with respect to maximum gas product yield of $31.98 \%$ as depicted in Figure 5.

\subsection{Characterization of Liquid Fuel Product}

Identification and composition of main hydrocarbons components of the liquid fuels product was done using GC-MS analysis as presented in Table 5. From the table, modified RCC catalyst waste at the above optimum operating conditions could produce hydrocarbonbased liquid fuels within the range of gasoline $\left(\mathrm{C}_{4}\right.$ $\mathrm{C}_{13}$ ) as listed in the Table 5. However, main product of hydrocarbon is shown for $\mathrm{C}_{13} \mathrm{H}_{28}(38.27$ 
\%) identified as n-tridecanol in GC-MS library [25]. From the analysis, calorific value of the liquid fuel product is $44,768 \mathrm{~kJ} / \mathrm{kg}$. Heating values of samples used were attained in accordance with ASTM D2015 [26]. The results of hydrocarbons range are in accordance with the results of Aguado et al. [27]. It can be seen that the productions of gasoline are very high as reported by De La Puente et al. [1617] which is similar with this research.

The hydrocarbons range of liquid fuel product could be controlled by varying reactor temperature and type of catalyst [27]. Catalyst configuration and reactor design is also essential towards the control of product hydrocarbons range with respect to effective contact between liquid and vaporized plastic sample with the catalyst bed. In this research, the catalyst was divided into two positions, i.e. below plastic sample and above plastic sample at the top section of reactor tube. The reactor and catalyst configuration/position is purposed to enhance the contact between vaporized plastic samples with the catalyst surface effectively.

\section{Conclusion}

From Response Surface Methodology method, optimum operating parameters of reactor temperature and catalyst weight were achieved with respect to maximum liquid and gas fuels yield. Optimum operating conditions of reactor temperature $550{ }^{\circ} \mathrm{C}$ and catalyst weight 1.25 gram were produced with respect to maximum liquid product yield of $29.67 \%$. Meanwhile, maximum yield of gas fuel product of $31.98 \%$ was also resulted at optimal reactor temperature of $550{ }^{\circ} \mathrm{C}$ and catalyst weight of 0.9 gram. The liquid fuel product consists of gasoline range hydrocarbons $\left(\mathrm{C}_{4}-\mathrm{C}_{13}\right)$ with high heating value $(44,768 \mathrm{~kJ} / \mathrm{kg})$.

\section{Acknowledgments}

The authors would like to express their sincere gratitudes to the Directorate General for Higher Education (DIKTI) Republic of Indonesia for the financial support received under the project of HIBAH KOMPETENSI GRANT YEAR 2010. The authors would also like to thank to Dr. Hery Haeruddin (LIPI) for his assistance on electric furnace fabrication as well as Retno Pujiastuti and Yunita Ariyani for their assistance on experimentation works.

\section{References}

[1] T.J. Appleton, R.I. Colder, S.W. Kingman, I.S. Lowndes, A.G. Read. (2005). Applied Energy, 81, 85-11

[2] B. V. Babu, A. S. Chaurasia, (2003). Energy Conversion Management, 44, 2135-2158.

[3] H. Huang, L. Tang, (2007). Energy Conversion Management, 48, 1331-1337.

[4] G. Manos, A. Garforth, J. Dwyer, (2000). Industrial Engineering Chemistry Research, 39, 1198-1202

[5] A.R. Songip, T. Masuda, H. Kuwahara, K. Hashimoto. (1993). Applied Catalysis B: Environmental, 2, 153-164

[6] Y. Ishihara, H. Nanbu, T. Ikemura, T. Takesue, (1990). Fuel, 69, 978-984

[7] Y. Sakata, M.A. Uddin, A. Muto, (1999). Journal of Analytical and Applied Pyrolysis, 51, 135-155

[8] Y. Uemichi, Y. Kashiwaya, M. Tsukidate, A. Ayame, H. Kanoh, (1983). Bulletin of Chemical Society of Japan, 56, 2768-2773

[9] Y.H. Lin, M.H. Yang, (2005), Journal of Molecular Catalysis A: Chemical, 231, 113-122

[10] Y. Uemichi, J. Nakamura, T. Itoh, M. Sugioka, (1999). Industrial Engineering Chemistry Research, 38, 385-390

[11] A. Marcilla, A. Gomez-Siurana, F. Valdes, (2008). Microporous Mesoporous Materials, 109, 420-428

[12] A. Marcilla, A. Gomez.Siurana, F. Valdes, (2007). Journal of Analytical and Applied Pyrolysis, 79, 433442

[13] S. Ali, A.A. Garforth, D.H. Harris, D.J. Rawlence, Y. Uemichi, (2002). Catalysis Today, 75, 247-255

[14] S.C. Cardona, A. Corma, (2000). Applied Catalysis B: Environmental, 25, 151-162

[15] N.S. Akpanudoh, K. Gobin, G. Manos, (2005). Journal of Molecular Catalysis A: Chemical, 235, 67-73

[16] G. De la Puente, C. Klocker, U. Sedran, (2002). Applied Catalysis B: Environmental, 36, 279-285

[17] G. De la Puente, J.M. Arandes, U.A. Sedran, (1997). Industrial Engineering Chemistry Research, 36, 4530-4534

[18] D.P. Serrano, J. Aguado, J.M. Escola, (2000). Industrial Engineerng Chemistry Research, 39, 11771184

[19] J. Aguado, J.L. Sotelo, D.P. Serrano, J.A. Calles, J.M. Escola, (1997). Energy Fuels, 11, 1225-1231

[20] D.P. Serrano, J. Aguado, J.M. Escola, (2000), Applied Catalysis B: Environmental, 25, 181-189

[21] D.C. Montgomery, (2001). Design and Analysis of 
Experiments, John Wiley \& Sons, New York

[22] G.M. Clarke, R.E. Kempson, (1997). Introduction to the Design and Analysis of Experiments, Arnold, London.

[23] J.A. Cornell, (1990). How to Apply Response Surface Methodology, American Society for Quality Control, Wisconsin.

[24] G.E.P. Box, W.G. Hunter, J.S. Hunter, (1978). Statistics for Experimenters: An Introduction to Design, Data Analysis, and Model Building, John Wiley \& Sons, New York
[25] Ji-lu Zheng, Xi-feng Zhu, Qing-xiang Guo, Qing-shi Zhu. (2006). Waste Management. 26, 1430-1435.

[26] P. Thipkhunthod, V. Meeyoo, P. Rangsunvigit, B. Kitiyanan, K. Siemanond and T. Rirksomboon. (2005). Fuel, 84, 849-857.

[27] J. Aguado, D.P. Serrano, G. San Miguel, (2007). Journal of Polymer \& Environment, 15, 107-118.

[28] W. L. Yoona, J. S. Parka, H. Junga, H. T. Leea, D. K. Leeb. (1999). Fuel. 78, 809-813 